\title{
CORRECTION
}

\section{Correction to: Imaging findings of lesions in the middle and posterior mediastinum}

\author{
Yoshiyuki Ozawa $^{1}$ (]) $\cdot$ Marehiko Hiroshima $^{1} \cdot$ Hiroyuki Maki $^{1} \cdot$ Masaki Hara $^{2} \cdot$ Yuta Shibamo $^{1}$
}

Published online: 18 January 2021

(C) Japan Radiological Society 2021

\section{Correction to: Japanese Journal of Radiology https://doi.org/10.1007/s11604-020-01025-0}

In the original publication, the affiliations of authors were incorrectly published.

The correct affiliations are given in this Correction. The original article has been corrected.

Publisher's Note Springer Nature remains neutral with regard to jurisdictional claims in published maps and institutional affiliations.

The original article can be found online at https://doi.org/10.1007/ s11604-020-01025-0.

Yoshiyuki Ozawa

ykiooster@gmail.com; yoshioza@med.nagoya-cu.ac.jp

1 Department of Radiology, Nagoya City University Graduate School of Medical Sciences, 1 Kawasumi Mizuho-cho Mizuho-ku, Nagoya 467-8601, Japan

2 Department of Radiology, Nagoya City West Medical Center, Nagoya, Japan 